\title{
Reflexões sobre a ética e a atuação profissional do Bibliotecário
}

\author{
Considerations about ethics and the Librarian \\ professional performance
}

Ana Cristina MISCHIATI ${ }^{1}$

Marta Lígia Pomim VALENTIM²

RE S U M O

Discute a importância da ética na atuação profissional do bibliotecário, ressaltando a sua atuação perante as mudanças de paradigmas e a sua influência sobre o comportamento profissional nas diferentes unidades de informação e nos diversos contextos sociais, políticos e econômicos. Inclui reflexões sobre a postura profissional do bibliotecário e o seu entendimento quanto à responsabilidade social da profissão.

Palavras-chave: ética, atuação profissional, bibliotecário, biblioteconomia, profissional da informação, postura profissional, Ciência da Informação.

\section{A B S T R A C T}

This paper discusses the importance of ethics in the librarian's professional performance, considering such performance as being confronted with changes of paradigms, while being influential on professional behavior within the various information units and the diverse economic, political, and social contexts. It discusses, also, the librarian's professional posture and understanding regarding the social responsibility in the profession.

Key words: ethics, professional performance, librarian, library science, information professional, professional behavior, Information Science.

\footnotetext{
1 Graduada em Biblioteconomia pela Universidade Estadual de Londrina. Atua em empresa privada na área de papel e celulose. E-mail: <amischiatti@yahoo.com.br>.

2 Doutora em Ciências da Comunicação pela ECA/USP. Líder do Grupo de Pesquisa "Informação, Conhecimento e Inteligência Organizacional”. Docente, Universidade Estadual de Londrina. Campus Universitário, Cidade Universitária, 86051-970, Londrina, PR, Brasil. Correspondência para/Correspondence to: M.L.P. VALENTIM. E-mail: <valentim@uel.br>.

Recebido em 4/4/2005 e aceito para publicação em 1/8/2005.
} 


\section{N T R O D U Ç Ã O}

As discussões sobre ética têm sido uma constante no âmbito das mais diferentes áreas do conhecimento. Na Biblioteconomia isso não é diferente: na área bibliotecária abre-se a discussão sobre como os seus profissionais vêm exercendo a profissão, bem como de que forma agem em relação à responsabilidade social.

Compreender a ética como ação permite relacioná-la diretamente com a cultura, ou seja, com o meio onde se está inserido, envolvendo costumes e crenças, representativas das escolhas individuais. Singer (2002, p.29) afirma que "as crenças e os costumes sob os quais nos criaram podem exercer uma grande influência sobre nós".

Percebe-se que, os conceitos de valores de cada grupo dentro de uma sociedade, podem intervir e influenciar condutas suscetíveis à argumentação, à crítica e, até mesmo, ao julgamento.

A ética, quando da sua conceituação, não deve, ou ao menos não deveria ser confundida com a moral. Entende-se que a moral é uma regulação dos valores e comportamentos considerados legítimos por uma determinada sociedade, com seus costumes, sua crença e sua tradição cultural, assim como há entendimentos morais específicos dentro de pequenos grupos sociais, como em instituições, em grupos políticos etc. (VALENTIM, 2004, p.56-58). A partir da compreensão desse conceito, pode-se afirmar: a moral é um fenômeno social particular que não tem compromisso com a universalidade, ou seja, com o que é válido e de acordo com o direito para todos os homens.

Fatores como o tecnológico, o científico e o sociocultural estão diretamente relacionados com a transformação pela qual vem passando a sociedade. Esses fatores permitem reinventar novos modelos e diferentes estilos de vida, além de contribuírem para uma mudança no comportamento dos indivíduos, de forma que seria imprudência afirmar que uma confusão de valores não afetaria a prática das condutas e ações éticas cotidianas.

Além desses fatores, contam-se as transformações na economia e na política, pois também essas são influenciadoras das condutas éticas nas relações humanas, ainda que se possa atribuir à política um maior percentual de influência nas condutas éticas de um indivíduo vivendo em sociedade.

O convívio em sociedade permite que cada indivíduo defenda interesses, crenças, costumes, etc.; de acordo com suas necessidades: "as escolhas são feitas ao sabor do acaso: hoje decide-se assim, atendendo a esses interesses; amanhã decide-se de outro jeito pois os interesses já são outros". (MARTINS, 1994, p.3). Por outro lado, permite também confrontar os desejos de fazer o bem, através de ações públicas, por meio de interferências políticas, como bem retrata Martins (1994, p.4): "não basta saber fazer bem o dever, é necessário poder fazer bem o dever". A partir desta idéia, há que repensar o dilema de estarem as ações e as práticas deliberadamente distantes do discurso ético.

Sendo a informação um instrumento essencial para o exercício da cidadania, porquanto possibilita ao indivíduo compreender as transformações que estão alterando o panorama mundial, e sendo o profissional bibliotecário responsável pela sua mediação, cabendo-lhe fazer valer, no âmbito informacional, os interesses coletivos em benefício da sociedade, discute-se neste trabalho a responsabilidade com que essas atividades estão sendo desenvolvidas; discute-se também se estes profissionais apresentam uma conduta ética e se possuem, de fato, um compromisso social com a coletividade.

Tratar da ética em relação ao comportamento das pessoas é extremamente complexo; principalmente, porque envolve os valores de uma determinada sociedade, os quais, por sua vez, tendem a julgar criticamente os aspectos 
acríticos de uma moral vigente. Aqueles valores constituem-se a partir da compreensão individual da influência cultural e, portanto, são valores inteiramente contestáveis. Entretanto, a ética, tanto quanto a moral, não forma um conjunto de verdades fixas. A ética se move, se amplia historicamente: basta lembrar que, em muitas épocas e diversas sociedades, a escravidão, sob uma ou outra forma, foi considerada natural.

No mundo atual, muitas profissões elaboraram diretrizes éticas, com o objetivo de orientar aqueles que as exercem. A Biblioteconomia, não constituindo exceção à regra, procurou garantir à sociedade, por meio da criação de princípios éticos biblioteconômicos, que as atividades desenvolvidas por seus profissionais não representem interesses pessoais, mas sim, signifiquem uma efetiva contribuição à coletividade.

De acordo com a literatura, a ética é a ciência da conduta, "é a ciência que visa o discernimento e a apreciação do bem e do mal, quanto a sua efetividade na conduta humana e da sociedade". (CÔRTE, 1994, p.18). Ferreira (1988, p.280), define ética como "estudo dos juízos de apreciação referentes à conduta humana suscetível de qualificação do ponto de vista do bem e do mal, seja relativamente à determinada sociedade, seja de modo absoluto". O termo ético significa, portanto, tudo aquilo que ajuda a tornar melhor o ambiente no qual vivemos. Por isso mesmo, o fator econômico, as novas tendências tecnológicas, bem como o meio e a cultura em que se integram os cidadãos, são assuntos de constante discussão, os quais podem afetar a ética das pessoas. Para Vergueiro (1994, p.8):

[...] esse aumento de interesse pela discussão das implicações éticas da profissão, muito se deve ao aparecimento das novas tecnologias informacionais, preocupações quanto a possíveis restrições ao acesso às informações armazenadas em bancos e bases de dados, bem como à privacidade quanto ao uso dessas informações seja outro fator importante a ser discutido.

O comportamento ético está diretamente relacionado à liberdade de escolha dos indivíduos. A ética nasce de uma escolha individual, seja ou não do grupo, no qual o sujeito ético só existe quando tende a conhecer a existência do outro, interagindo e respeitando os limites individuais e coletivos e as diferenças, o maior desafio nas relações humanas. De acordo com Martins (1994, p.3):

[...] a vida moral e o comportamento ético só são possíveis se considerarmos o homem livre, autônomo, dono de seus atos. Sem liberdade, não se pode falar em escolha e, portanto, em ação ética.

É importante estimular e difundir o desenvolvimento de princípios éticos na formação profissional, com foco no compromisso social da profissão, para o exercício da cidadania. Entende-se que a construção da ética está associada a um processo educativo, que se desenvolve desde a infância e evolui a partir das relações sociais e afetivas que se mantêm com o coletivo.

Refletir sobre o comportamento do profissional bibliotecário, diante das transformações pela qual a sociedade vem passando, e estabelecer uma relação entre sua conduta e a conscientização do seu papel e compromisso social na atuação profissional, é essencial.

\section{É T I C A}

A ética é uma característica inerente a toda ação humana e, por essa razão, é um elemento vital na produção da realidade social. A ética está relacionada à opção, ao desejo de realizar-se na vida e de manter com os outros, relações justas e aceitáveis. Vasquez (1985, p.19) afirma que todo homem possui um senso 
ético, uma espécie de "consciência moral". Ele está constantemente avaliando e julgando suas ações para saber se são boas ou más, certas ou erradas, justas ou injustas. Geralmente esse senso ético está fundamentado nas idéias de bem e virtude, ou seja, em valores perseguidos por todo ser humano e cujo alcance se traduz numa existência plena e feliz.

Singer (2002, p.31) afirma que "os comportamentos humanos podem ser classificáveis sob a ótica do certo e errado, do bem e do mal". Embora relacionadas ao agir individual, essas classificações sempre têm relação com as matrizes culturais que prevalecem em determinadas sociedades e contextos históricos.

Segundo o pensamento de Vasquez (1985, p.23), "o homem só realiza sua existência no encontro com outros homens"; portanto, a ação e a decisão de um homem não envolvem apenas a si próprio, mas também outras pessoas e, até mesmo, uma comunidade inteira que poderá sofrer as conseqüências dessas ações e decisões. Para Hare (2003, p.206), quando se toma uma decisão moral sobre uma determinada situação

[...] temos de tratar os interesses, as preferências das pessoas diferentes afetadas por nossas ações como de igual importância, com pesos iguais. Isso é o mesmo que mostrar igual preocupação e respeito por todos.

Nessa convivência, naturalmente têm de existir regras que coordenem e harmonizem essas relações. Essas regras, dentro de uma sociedade ou de um grupo social, indicam os limites em relação aos quais se permite medir as possibilidades e as limitações a que o indivíduo deve se submeter.

Diante dos dilemas da vida, o indivíduo pratica determinados atos e, muitas vezes, valese de determinados argumentos para tomar decisões, justificar ações e, conseqüentemente, posicionar-se dentro da "normalidade", ou seja, dentro do que é aceito pela coletividade. Para isso, faz-se uso de normas que têm relação com o que é conhecido pela sociedade como valores morais.

A moral, conforme Singer (2002, p.42), pode ser entendida como "o conjunto das práticas cristalizadas pelos costumes e convenções histórico-sociais". Cada sociedade tem sido caracterizada por seus conjuntos de normas, valores e regras. São as prescrições e proibições do tipo "não matarás", "não roubarás", de cumprimento obrigatório. Muitas vezes, essas práticas são incompatíveis com os avanços e conhecimentos das ciências naturais e sociais.

"A moral é objeto da ética", como afirma Nalini (1998, p.67). Mas não se pode confundir a ética e a moral: é certo que toda moral supõe determinados princípios, normas ou regras de comportamento; entretanto, não é a ética que os estabelece numa determinada comunidade, embora estejam estritamente relacionados. A ética não cria a moral: ela é a ciência de uma forma específica de comportamento humano. Vasquez (1985, p.12) amplia a definição afirmando que "a ética é a teoria ou ciência do comportamento moral dos homens em sociedade. A ética seria então uma espécie de teoria sobre a prática moral".

De acordo com o raciocínio de Vasquez (1985, p.47), "a ética também estuda a responsabilidade do ato moral", ou seja, a decisão de agir numa situação concreta é um problema prático-moral, mas investigar se uma pessoa pôde escolher entre duas ou mais alternativas de ação e se agiu de acordo com sua decisão, é um problema teórico-ético, porquanto busca verificar se houve liberdade ou determinismo na realização dos seus atos. Singer (2002, p.26) explica:

[...] a ética não constitui um sistema ideal, que seja sobre a teoria, mas que não funcione na prática. $O$ contrário disso está mais próximo da verdade: um juízo ético que não funcione na prática deve igualmente padecer de um 
defeito teórico, pois o objetivo essencial dos juízos éticos é orientar a prática.

Se o determinismo é total, então não há espaço para a ética: esta se refere às ações humanas; entretanto, se essas ações estão totalmente determinadas de fora para dentro, não há qualquer espaço para a liberdade, para a autodeterminação e, conseqüentemente, para a ética.

Vasquez (1985, p.85) atribui à ética o propósito de contribuir para fundamentar ou justificar certa forma de comportamento moral. Assim, se a ética revela uma relação entre o comportamento moral e as necessidades e interesses sociais, ela ajudará a situar no devido lugar a moral efetiva do grupo social. Por outro lado, ela permite ao indivíduo exercitar uma forma de questionamento, no qual se confronta o dilema entre "o que é" e "o que deveria ser", dando-lhe possibilidade de imunizar-se contra a assimilação dos valores e normas vigentes na sociedade, ao despertar a desconfiança de que tais valores e normas possam estar encobrindo interesses que não correspondam às próprias causas geradoras da moral.

A reflexão ética também permite a identificação de valores petrificados que não mais satisfazem os interesses da sociedade a que servem. Singer (2002, p.212) afirma:

[...] uma vez contestada, a ética tradicional se desintegra. As mudanças na tecnologia afetam e alteram a forma de pensar a ética, principalmente para os que foram educados para aceitar a ética tradicional como algo acima de qualquer contestação.

Já a moral pode ser entendida como um conjunto de regras obrigatórias que estão relacionadas diretamente com o que é satisfatório em termos de bem e de boa conduta para uma sociedade. Explica Vasquez (1985, p.93), “[...] a ética não estabelece regras de conduta moral. A moral está relacionada com a prática de um sistema aceito harmoniosamente pela sociedade".

Alguns grupos sociais dentro da sociedade baseiam-se em comportamentos individuais relacionados ao fator religioso para apoiar decisões e ações cotidianas, o cumprimento, pode-se assim dizer, de uma conduta ética. Não é função da ética formular juízos de valor quanto à prática moral de outras sociedades, mas explicar a razão de ser dessas diferenças e o porquê de os homens terem recorrido, ao longo da história, a práticas morais diferentes e até opostas.

A vida ética consiste na interiorização dos valores, normas e leis de uma sociedade, condensados na vontade objetiva cultural, por um sujeito moral que as aceita livre e espontaneamente, através de sua vontade subjetiva individual; vale dizer, é a aceitação harmoniosa da vontade coletiva de uma cultura que, com o passar do tempo, se concretiza e se fortalece dentro de uma sociedade, em especial, no âmbito das profissões.

\section{Ética profissional}

Se foram os gregos os precursores da ciência filosófica na história da humanidade, talvez isso se deva a um comportamento estabelecido pelas divisões de classes sociais, como registra a própria história.

A ética profissional também teve suas origens na Grécia Antiga, no período em que as organizações do trabalho não eram norteadas pelas profissões e, sim, pelo trabalho escravo. No século $X X$, mais especificamente na década de 80, a ética profissional surge nas empresas, devido à redução das hierarquias, o que, conseqüentemente, fez diminuir a autonomia das pessoas. A partir daí, com a diminuição dos organogramas nas empresas, o nível de competição para obtenção de cargos mais altos aumenta, dando espaço à concorrência. Como 
o objeto da ética profissional é justamente conseguir a convivência com outros profissionais e profissões, estabeleceu-se uma ordem necessária ao bem comum, cuja virtude fundamental é a honestidade (MOTA; SILVA, 2003, p.3).

Compreende-se que ética é um tema complexo, pois envolve o homem em todas as suas relações sociais, quer no exercício da profissão, quer na sua convivência com os outros homens. Explica Rios (1997, p.77):

Fala-se numa crise ética em nossa sociedade contemporânea. Talvez seja o grande desafio que se apresenta à competência. Fala-se numa crise ética, ou melhor, numa crise moral, que provoca uma reflexão de caráter ético.

A ausência da ética pode ter-se tornado uma adaptação progressiva do homem perante as condições de vida, tanto para com ele próprio, quanto para com o grupo a que pertence; basta lembrar a crise social, política e econômica que ora assola o mundo, como as diferentes formas de violência contra a criança, os idosos, e a mulher, o preconceito racial, o terrorismo, o egoísmo, as diferenças sociais que podem resultar na ausência de ética. Rodrigues (1994, p.5) afirma que "as pessoas podem fazer aquilo que bem entenderem, ainda assim, estarem vivendo de acordo com padrões éticos, se estiverem prontas a defender e justificar suas ações".

De acordo com Nash (1993, p.109), dada a tendência do homem de pensar em si próprio como uma boa pessoa, e dado o fato de as intenções da maioria dos profissionais geralmente serem boas, os resultados anti-éticos podem facilmente ser desprezados ou racionalizados.

Do ponto de vista econômico, os mercados financeiros impõem suas premissas, fortalecendo o fenômeno da globalização que atinge os países dos diferentes continentes, ditando as normas e estabelecendo outros tipos de relações humanas e sociais, nas quais a competitividade, o individualismo e o domínio das tecnologias se estabelecem como as palavras de ordem no atual mundo globalizado.

Do ponto de vista profissional, os reflexos da globalização e dos avanços da ciência no sentido lato, vêm afetando significativamente o mundo do trabalho e, conseqüentemente, a formação de profissionais nas diferentes áreas do conhecimento. Entretanto, a prática democrática deve ser desenvolvida, assegurando-se de que tanto o indivíduo quanto a sociedade utilizem meios emancipatórios que não podem ser confundidos com massificação ou globalização (FARIA, 1994, p.14).

A situação da ética nas sociedades modernas difere daquela nas sociedades tradicionais, nas quais as instituições representavam um modo de ser predominante. Para Côrte (1994, p.19), a situação é caracterizada pelo pluralismo dos comportamentos e dos valores: "Não há mais um costume, mas vários; não uma ética, e sim muitas".

O convívio em sociedade certamente irá estabelecer e apontar as diferenças entre os indivíduos; mas, se o profissional souber reconhecer essas diferenças e fizer com que se tornem, não uma ameaça, mas uma forma de crescimento intelectual e cultural, com certeza tornará esse convívio muito mais harmonioso.

Tais reflexões são ou não aplicáveis à Biblioteconomia? A resposta à esta questão implica em conhecer melhor a situação desse tema em nosso contexto.

\section{Ética e a Biblioteconomia}

A Biblioteconomia constitui uma profissão de natureza sócio-humanista, que se caracteriza como prestadora de serviços de informação, diretos e indiretos, à sociedade, e como mediadora entre o mercado consumidor e o produtor de informação. Os profissionais atuando 
nessa área necessitam dominar certas competências e habilidades sociais, técnicas e tecnológicas, condição necessária para o alcance dos objetivos social e ético.

A atuação profissional, por causa dos diferentes contextos socioeconômicos, se dá em todos os níveis e para todos os segmentos sociais. A atuação profissional busca atingir os objetivos da instituição onde se desenvolvem as atividades inerentes à profissão, bem como objetiva a satisfação dos diferentes públicos, sobretudo os reais (preferenciais). Vergueiro (1994, p.9) afirma:

\section{[...] os bibliotecários devem coletar e fornecer, sem quaisquer tipos de restrições, todas as informações necessárias a seus usuários, sem questionar a aplicação que eles farão das informações recebidas.}

Espera-se que os profissionais bibliotecários sejam capazes de atuar de forma crítica, criativa e eficaz na identificação de demandas por informações de toda natureza e nível de complexidade, bem como no processamento de informações em diferentes documentos e suportes físicos, mediante a aplicação de conhecimentos teórico-práticos de coleta, tratamento, armazenamento, disseminação, busca e recuperação, apoiados nas tecnologias disponíveis e no gerenciamento de serviços e recursos informacionais e, também, através das suas ações nas áreas de planejamento, organização, administração e assessoria.

É da competência do profissional bibliotecário a prestação de serviços em redes e sistemas de informação, como também o monitoramento do desenvolvimento social e avanços científicos e tecnológicos, por meio de ações culturais e de pesquisas relacionadas com o uso e o valor da informação.

O bibliotecário tem competência e habilidade para economizar tempo e dispor de recursos para seu público, colocando ao alcance deste, informações selecionadas, precisas e de fundamental importância para eles. Suas competências e habilidades alcançam méritos cada vez mais relevantes, dentro da nova realidade tecnológica e sociocultural. O profissional bibliotecário está habilitado a executar a gestão de serviços bibliotecários, planejamento físico de bibliotecas e centros de documentação e informação, além da organização de acervos (bibliográficos ou não), a execução dos serviços técnicos e administrativos ligados à documentação, a avaliação, a prestação de serviços de assessoria, de consultoria e de ensino, como, também a fiscalização técnica, a normalização de documentos, a análise de trabalhos técnicos e científicos, a organização e o gerenciamento de bases de dados virtuais, de Intranets, de documentação para processos de certificação de qualidade, de avaliação de conteúdo da Internet, de documentos relacionados a patentes, entre outras habilidades.

O bibliotecário é capaz de atuar em qualquer função que vise à organização, ao processamento e à recuperação de informações, é capaz de gerir a informação e o conhecimento; enfim, é capaz de atender às necessidades e demandas de informação da sociedade.

Os profissionais da informação são ainda responsáveis pela geração de produtos, formulação e execução de políticas institucionais de informação; pela elaboração, coordenação, execução e avaliação de planos, programas e projetos que traduzam as efetivas necessidades informacionais de indivíduos, grupos e comunidades nas mais diversas áreas do conhecimento e mercado, seja através de vínculo empregatício ou de forma autônoma.

O campo de atuação da Biblioteconomia, que antes compreendia basicamente apenas alguns tipos de unidades de informação, expandiu-se para poder atender à explosão editorial e à diversificação dos tipos de documentos e suportes informacionais necessários às organizações públicas e privadas e à Sociedade da Informação. 
Essa nova realidade profissional pode ser claramente observada, por meio da Classificação Brasileira de Ocupações que insere o bibliotecário na família 2612 - Profissionais da Informação, com a seguinte descrição:

Disponibilizam informação em qual-
quer suporte; gerenciam unidades
como bibliotecas, centros de documen-
tação, centros de informação e correla-
tos, além de redes e sistemas de
informação. Tratam tecnicamente e
desenvolvem recursos informacionais;
disseminam informação com o objetivo
de facilitar o acesso e geração do
conhecimento; desenvolvem estudos
e pesquisas; realizam difusão cultural;
desenvolvem ações educativas.
Podem prestar serviços de assessoria
e consultoria.

Segundo Nalini (1998, p.52), as constantes mudanças nas relações com as novas tecnologias alteram os processos pelos quais se transmitem os constantes fluxos de informação entre as pessoas, provocando alterações nos usos e costumes em amplas esferas sociais, políticas, econômicas e culturais.

Pode-se afirmar que o exercício da cidadania é uma prática social e política que necessita de certas condições para se efetivar. Essas condições, porém, podem depender do estágio de emancipação do próprio homem, que se processa no seu cotidiano, de modo individual e coletivo, e resulta do confronto entre classes ou entre iguais e desiguais.

Para Paletta e Paletta (1999, p.12), ser cidadão significa ser "sujeito social consciente e politicamente organizado, capaz de conceber e realizar projeto próprio de confronto social com os privilegiados do sistema".

Assim, o que pode tornar uma sociedade mais cidadã do que outra é seu talento para gerir suas desigualdades culturais, políticas, sociais e econômicas, construídas ao longo do tempo.

[...] os processos de emancipação e de cidadania irão depender, em grande parte, do próprio sujeito social e das suas etapas de socialização. Dá-se de dentro para fora como qualquer outro processo educativo, iniciando-se com uma postura crítica de reconhecimento e recusa das suas condições de existência, ressaltando que o salto qualitativo dependa sempre das suas competências teórica e prática. (PALETTA; PALETTA, 1999, p.13).

$\mathrm{Na}$ Biblioteconomia, busca-se privilegiar o cumprimento da função social das unidades, sistemas e serviços de informação, com amparo nos princípios da regulamentação profissional.

A profissão de bibliotecário caracterizase como uma profissão de prestação de serviços à sociedade, de comunicação e de contato direto e indireto com o público: produtores e consumidores de informação. O profissional bibliotecário está no centro das ações de produção, tratamento, disseminação, transferência e uso das informações.

\section{Código de ética profissional}

Observa-se que quase todos os discursos sobre as profissões, nas diversas áreas do conhecimento, têm tido como principal enfoque a ética e seus códigos. O Código de Ética Profissional é o conjunto das normas de conduta do profissional bibliotecário que, na qualidade de pessoa física e jurídica, objetiva contribuir para a formação e o comprometimento com o fazer bibliotecário. O Código de Ética visa instrumentalizar e apoiar as tomadas de decisão do bibliotecário no exercício da profissão, além de ser um importante referencial para a atuação do profissional no desempenho do seu papel na sociedade.

Em seus quarenta e dois anos de existência, o Código de Ética passou por reformulações, com o objetivo de adequar-se e aprimorar-se às necessidades sociais, e às mudanças no mundo do trabalho. 
Desde a sua criação, - o primeiro Código de Ética do Profissional Bibliotecário foi aprovado em 1963, no IV Congresso Brasileiro de Biblioteconomia e Documentação (CBBD), em Fortaleza - até os dias de hoje, o Código de Ética passou por seis alterações, sendo a última realizada em 2001.

Os códigos de ética são instrumentos de conscientização sobre as ações, os direitos e os deveres profissionais para com a sociedade. Nesse sentido, o código tem por finalidade apontar diretrizes para o cumprimento das obrigações profissionais, o que implica em atender às necessidades e demandas do poder público, da iniciativa privada e da sociedade em geral.

\section{Ética na formação do profissional bibliotecário}

Para discutir os conteúdos formadores das escolas de Biblioteconomia no país, faz-se necessário observar, primeiramente, que as diferenças geográficas representam fatores relevantes, os quais influenciam a elaboração das diretrizes do curso. Valentim (2002, p.118) afirma: "falar sobre as competências e habilidades necessárias ao profissional da informação exige uma reflexão sobre as especificidades de cada região do país e sua relação com as demandas sociais existentes".

Ao refletirmos sobre a formação e o desempenho do bibliotecário, consideramos indubitavelmente o fato de tratar-se de uma profissão regulamentada por lei federal, que exige do profissional um saber técnico-científico graças ao qual ele pode oferecer ao cidadão a prestação de serviços de qualidade. A qualidade do trabalho, que envolve competências e habilidades, leva a considerar uma dimensão ética presente na prática profissional, a qual supõe aspectos técnicos e políticos. Para Valentim (2002, p.118) "[...] atuar de forma profissional, antes de mais nada, é agir com responsabilidade no uso dos diferentes recursos e instrumentos da profissão que atenda os diferentes públicos existentes".

Qualquer que seja a área de atuação dos indivíduos, a ética faz parte da competência profissional, do domínio dos conhecimentos necessários para o indivíduo desempenhar seu papel na sociedade, articulado com o domínio das técnicas e das estratégias para realização do seu trabalho, inclusive o do bibliotecário.

Assim, o caráter ético da profissão é determinado pela qualidade das ações realizadas pelos indivíduos que as exercem, incorporando os valores assumidos como ideais pelo grupo profissional em questão. A profissão é, portanto, "uma atividade pessoal, desenvolvida de maneira estável e honrada, a serviço de outros e em benefício próprio, de conformidade com a própria vocação e em atenção à dignidade da pessoa humana". (NALINI, 1998, p.145).

Os indivíduos imbuídos dos princípios característicos da profissão encontram, na ética, um espaço de reflexão crítica, sistemática, sobre os valores presentes na ação bibliotecária, estabelecendo princípios norteadores da conduta profissional, os quais contribuem para dirimir dúvidas e solucionar conflitos.

Se forem consideradas todas as atribuições e obrigações socioculturais, isto é, o que se considera viver dentro dos padrões éticos em benefício da sociedade, é primordial compreender a importância da formação para a cidadania, principalmente em se tratando de ética.

Pensar eticamente inclui reconhecer que os próprios interesses não podem contar mais que os interesses de outros. Além disso, deve-se observar que em lugar dos próprios interesses é preciso levar em consideração os interesses de todos os que são atingidos por uma decisão, o que levaria um indivíduo a agir de forma a pesar todos os interesses e adotar ações mais direcionadas a maximizar os benefícios aos interesses dos atingidos. 


\section{Dilemas éticos profissionais}

A necessidade de criar um código de ética para as profissões talvez se deva, num primeiro momento, à existência dos dilemas éticos que rodeiam os ambientes profissionais de diversos níveis e especificidades. Esses dilemas podem surgir das diferenças culturais entre os indivíduos inseridos num âmbito mais amplo da esfera social. Outro fator que se considera importante para explicar a existência de conflitos éticos no ambiente profissional, são as desigualdades sociais, aliadas à má distribuição de renda e à exclusão social, que atingem a sociedade de forma ampla, envolvendo a educação, a saúde, a política econômica etc.

Segundo Souza (2002, p.135), a sociedade, ou seja, o espaço público da atuação profissional, coloca o

bibliotecário em contato com todas as manifestações da existência humana [...] o bibliotecário se relaciona, conscientemente ou não, com todos os saberes, com todos os humores pessoais do público a que atende, o qual, por sua vez, é motivado por todos os tipos de influência.

Em determinadas situações, para os profissionais bibliotecários, torna-se difícil proceder com ética no exercício profissional, devido aos problemas encontrados nas unidades de informação, seja na biblioteca pública, na biblioteca especializada, na biblioteca universitária, seja em outros tipos de bibliotecas ou centros de documentação e informação.

Valentim (2002, p.60) descreve algumas situações comuns encontradas nas bibliotecas, para exemplificar quando o profissional bibliotecário necessita refletir sobre sua decisão: seja a de não permitir que o documento seja retirado porque é vetado que ele circule fora do ambiente da biblioteca, ou seja a de não permitir que um usuário faça cópias de um documento não obstante ser evidente que o usuário não possui recursos financeiros suficientes para adquirir o material.

Outro exemplo é o do profissional bibliotecário, responsável pela organização de uma biblioteca pública local, cujo objetivo é o de criar projetos de incentivo à leitura e à participação efetiva da comunidade. Tais projetos, evidentemente, devem desenvolver-se sem discriminações de qualquer natureza contra os usuários que tenham condições excepcionais de trabalho. Entretanto, apesar de contar com o total apoio da Administração Municipal, o bibliotecário responsável não leva em consideração que a biblioteca não possui rampas de acesso, ou que tão pouco dispõe de coleções especiais para públicos específicos como crianças, idosos e deficientes visuais! (SOUZA, 2002).

Os desafios são constantes nas práticas profissionais e os conflitos possíveis devem ser vistos pelos profissionais bibliotecários, não como questões pessoais, mas como resgate do conjunto de idéias que leva à formulação dos vários consensos políticos em torno dos direitos humanos; assim como devem também ser observadas as responsabilidades diante dos princípios biblioteconômicos, de forma a adequar os interesses de todos os envolvidos. Isso requer refletir sobre as duas ou mais verdades existentes, no momento da tomada de decisão, seja ela de qual natureza for.

\section{CONSIDERAÇÕ ES FINAIS}

É preciso discutir as questões relativas à ética na atuação profissional do bibliotecário, objetivando chamar a atenção de profissionais e estudantes, para que reflitam a respeito das questões éticas inerentes à profissão e desenvolvam um novo modo de pensar, observando o contexto global e tendo como ponto de partida as diferentes facetas da profissão, referentes à inseparabilidade do ambiente social, econômico e cultural e como estas se refletem na atuação profissional. 
Os acontecimentos mundiais dos últimos anos mostraram que há necessidade da mudança emergencial do paradigma mecanicista, que direcionava o pensamento mundial, para um novo paradigma mais holístico, que permita ao ser humano vivenciar a complexidade do pensamento.

No contexto da profissão bibliotecária cabe ao profissional estar atento a esta mudança paradigmática, atualizando seus conhecimentos sobre o mundo que o cerca, desenvolvendo uma ótica mais integral, inter- e multidisciplinar de sua profissão, discutindo os dilemas éticos que o envolvem, refletindo e questionando profundamente seu significado.

O bibliotecário situa-se na sociedade como um especialista que conhece certas técnicas e detém certas competências e habilidades para atuar de forma crítica na identificação de demandas informacionais de diversos tipos e graus de complexidade. Cabe a esse indivíduo criar em si mesmo um estado interno e profundo que o oriente em um sentido definido, isto é, que o leve a transferir esses valores para sua vida profissional.

\section{REFERÊ N CIAS}

CÔRTE, A.R. Por um comportamento ético ou pelo cumprimento de um código de ética. Palavra-Chave, São Paulo, n.8, p.18-20, 1994.

FARIA, E.M. A biblioteconomia e a ética. Palavra-Chave, São Paulo, n.8, p.14-17, 1994.

FERREIRA, A.B.H. Dicionário Aurélio básico da língua portuguesa. Rio de Janeiro: Nova Fronteira, 1988. p.280.

HARE, R.M. Ética: problemas e propostas. São Paulo: Editora UNESP, 2003. 252p.

MARTINS, M.H.P. A ética em questão. Palavra-Chave, São Paulo, n.8, p.3-4, 1994.

MOTA, F.R.L.; SILVA, I.S. Compromisso ético na sociedade da informação. In: ENCONTRO NACIONAL DE INFORMAÇÃO E DOCUMENTAÇÃO JURÍDICA, 8, 2003, Florianópolis. Anais... Florianópolis, 2003.
O Código de Ética é um conjunto de princípios destinados à tomada de decisão, no âmbito das profissões. Embora identificado como documento de relevância, fixando normas de conduta para os profissionais, não pode garantir que as ações dos profissionais primem pela excelência das atitudes éticas, como espera a sociedade.

Outro fator importante a ser discutido, é a importância de tratar, com certa primazia, a temática ética nas escolas de Biblioteconomia. Considera-se relevante que essa discussão seja abordada com os alunos para evidenciar os dilemas éticos profissionais provenientes das diferenças entre os indivíduos, tratando-se então de discutir e refletir sobre as questões éticas que regem a profissão e o Código de Ética.

É mister, ainda, despertar a consciência dos profissionais e estudantes de Biblioteconomia para a importância da ética na profissão, pois é um tema rico em reflexões e oportunidades de construção de um pensamento futurista e integral, da profissão e do mundo.

NALINI, J.R. Ética geral e profissional. São Paulo: Revista dos Tribunais, 1998. 281p.

NASH, L.L. Ética nas empresas: boas intenções à parte. São Paulo: Makron Books, 1993. 239p.

PALETTA, F.A.C.; PALETTA, F.C. O comportamento ético e sua influência na era da informação. São Paulo: USP, 1999. 15p. Disponível em: <www.ufpe. br/snbu/docs/50.a.pdf>. Acesso em: 15 maio 2004.

RIOS, T.A. Ética e competência. 5.ed. São Paulo: Cortez, 1997. 86p. (Questões da Nossa Época).

RODRIGUES, A.M.M. Tecnologia para o desenvolvimento humanizado. Ensaio, Rio de Janeiro, v.1, n.3, p.5-10, 1994.

SINGER, P. Vida ética: os melhores ensaios do mais polêmico filósofo da atualidade. Rio de Janeiro: Ediouro, 2002. 
SOUZA, F.C. Ética e deontologia: textos para profissionais atuantes em bibliotecas. Florianópolis: Editora UFSC; 2002, 165p.

VALENTIM, M.L.P. Ética profissional na área de Ciência da Informação. In: VALENTIM, M.L.P. (Org.). Atuação profissional na área de informação. São Paulo: Polis, 2004. p.55-69. (Coleção Palavra - Chave, 14).

VALENTIM, M.L.P. Formação: competências e habilidades do profissional da Informação. In:
VALENTIM, M.L.P. (Org.). Formação do profissional da informação. São Paulo: Polis, 2002. p.117-132. (Coleção Palavra - Chave, 13).

VASQUEZ, A.S. Ética. 8.ed. Rio de Janeiro: Civilização Brasileira, 1985.

VERGUEIRO, W.C.S. Ética profissional versus ética social: uma abordagem sobre os mitos da biblioteconomia. Palavra-Chave, São Paulo, n.8, p.8-11, 1994. 